\title{
Formwork Support Design of Roof of Subway Interval Engineering Based on Finite Element Analysis
}

\author{
Sujuan Li \\ Civil Engineering College, Tangshan University, Tangshan, Hebei 063000, China. Email:sujuanmail@163.com
}

The design of the formwork support for a certain section of the Beijing subway project was carried out in this paper. And the disk lock formwork support was used in the engineering.It was analyzed on the the design of the formwork support for the roof with the thickness of $1.5 \mathrm{~m}$ of the interval engineering. The manual calculation and the sap2000 finite element analysis were also used in the paper.The effect of the diagonal brace and its number were analyzed in addition to the design of the formwork support. It was showed that the axial force of the standing tube tends to be uneven with the increase of the number of slant bars in the framework. And the axial force of the standing tube connected to diagonal brace is larger than that of the framework without brace significantly. So it will be dangerous to the framework without considering the effect of it by the manual calculation.

Keywords: Disk Lock, Formwork Support, Steel Tubular Scaffold, Finite Element Analysis

\section{Introduction}

In recent years, with the increase of traffic pressure, the construction of rail transit projects in China has entered a period of vigorous development, especially in the city, there are more subway projects. When the surrounding environ-ment permits, the earthwork excavation of metro project will be carried out by open excavation. However, for the construction of the main structure roof, the design of its formwork support system will be very critical, which is related to the safe construction. Because of its unique disk lock, disk lock steel tubular scaffold achieved multi-directional and stable connection between members, and the structure has good integrity, not easy to twist, construction safety, at the same time, its erection and disassembly is fast, construction efficiency high. Many advantages make it more and more widely used in the formwork support system [1 3]. For safe construction, this kind of formwork support system was used in a section project of Beijing Metro Line 17, and the finite element analysis software SAP2000 was used to analyze it.

\section{Project Overview}

From the South Station of Yizhuang Station to the Ciqumen Station, along the planned green space and the plan-ned road, it extends from southeast to northwest through the Er Fenzhiqu and the entrance and exit line of the South Parking lot of the Ciqu, and then connects to the Ciqu Station. Open-cut method, mining method and shield tunneling method were adopted in this section. The main line section, single crossing section and cross crossing section were con-structed by open-cut method, which is a two-to-four-span frame structure. The main research scope of this paper was the two-span frame part of the four-line parallel open-cut section.

\section{Design of Formwork Support}

The difficulty in the design of formwork support in this section project was that the thickness of the roof is large, so the load of formwork support is large. In view of this, this paper focused on the design of the formwork of roof with the thick of $1.5 \mathrm{~m}$ which is the most difficult in this project. The formwork and support system for $1.5 \mathrm{~m}$ thick roof in this area are as follows:

\section{Shuttering}

Multi-layer board with the thick of $15 \mathrm{~mm}$ was used as the panel. $80 \times 80 \mathrm{~mm}$ wooden square with a spacing of $150 \mathrm{~mm}$ is used as the secondary corrugates. 185 aluminium beams with a spacing of $900 \mathrm{~mm}$ was used as the main corru-gates. The secondary corrugates of the formwork were arranged along the longitudinal direction, the main corrugates along the transverse direction, and the the multi-layer slabs were arranged on the secondary corrugates.

\section{Supporting System}

Disk lock steel tubular scaffold was used as the support system, with the space of $1500 \mathrm{~mm}$ (longitudinal) $\times 900 \mathrm{~mm}$ (transverse), lift height $1500 \mathrm{~mm}$.

The height of the formwork support in this section was about $5.5 \mathrm{~m}$, not more than $8 \mathrm{~m}$, and the height of the frame didn't exceed 4 steps, so it was not a tall formwork support.

The bottom longitudinal and transverse horizontal bars were used as bottom reinforcing tubes with the height of $500 \mathrm{~mm}$ from the ground, which met the requirements of JGJ231-2010" Techanical specification for safety of disk lock steel tubular scaffold in construction " [4]. U-head jack was used at the top of the standing tube. The length of the horizontal rod extending from the top of the standing tubes including the adjustable U-head jack was about $200 \mathrm{~mm}$, into the columns $250 \mathrm{~mm}$, outside 200 mm which accorded with JGJ231-2010.The vertical diagonal braces were set continuously from the bottom to the top of the formwork around, in the middle, vertically and horizontally. The angle between the diagonal braces and the ground is between $45 \sim 60^{\circ}$, and each step was connected with the column. Ac-cording to the above requirements, the supporting system of the frame for the roof of this section was finally determi-ned. The supporting structure of the cross-section frame is shown in Fig. 1, 
and the arrangement of the diagonal braces is shown in Fig. 2.

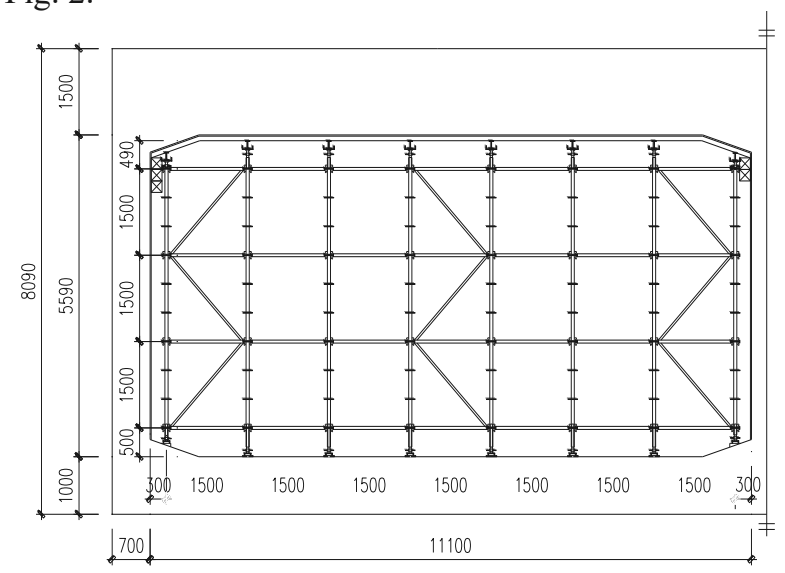

Fig. 1 Supporting Structure of Cross-section Form-work Support

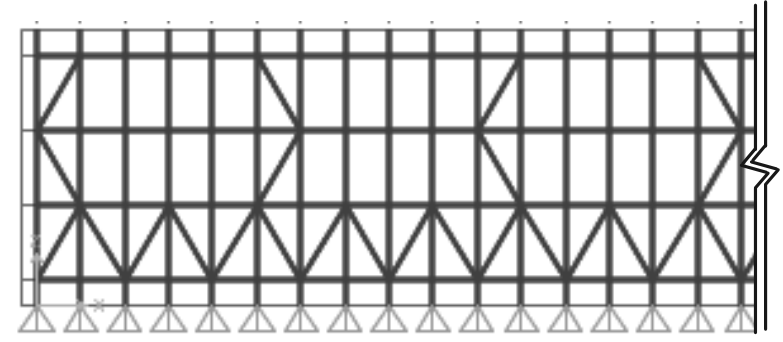

Fig. 2 Vertical View of the Diagonal Brace

\section{Computing of Formwork Support}

\subsection{Basic parameters}

The materials and characteristics of formwork support used in this project are shown in Table 1.

Tab. 1 Properties of materials

\begin{tabular}{|c|c|c|c|c|c|}
\hline Name & Steel grade & Specification & $\begin{array}{l}\text { Bending strength } \\
\left(\mathrm{N} / \mathrm{mm}^{2}\right)\end{array}$ & Shear strength $\left(\mathrm{N} / \mathrm{mm}^{2}\right)$ & elasticity modulus $\left(\mathrm{N} / \mathrm{mm}^{2}\right)$ \\
\hline Standing tube & Q345 & $\Phi 60 \times 3.2$ & 300 & - & $2.06 \times 10^{5}$ \\
\hline Ledger & Q235 & $\Phi 48 \times 2.5$ & 205 & - & $2.06 \times 10^{5}$ \\
\hline Diagonal brace & Q195 & $\Phi 33 \times 2.3$ & 175 & - & $2.06 \times 10^{5}$ \\
\hline Square timber & - & 80 & 13 & 1.4 & $9 \times 10^{3}$ \\
\hline 185 Aluminum beam & $6061 \mathrm{~T} 6$ & $100 \times 185$ & 200 & 115 & $0.7 \times 10^{5}$ \\
\hline Surface slab & - & - & 13 & - & $6 \times 10^{3}$ \\
\hline
\end{tabular}

In the design of formwork support for roof in this section, besides $1.5 \mathrm{~m}$ thick concrete dead weight load, $0.5 \mathrm{kN} / \mathrm{m} 2$ dead weight of formwork keel, $3 \mathrm{kN} / \mathrm{m} 2$ load of construction personnel and equipment and $2 \mathrm{kN} / \mathrm{m} 2$ vibration load were also considered.

\subsection{Computing of formwork support}

Because the force of the transversal bar and diagonal brace in the formwork support were small, this paper focused on the analysis of the main and secondary keel, and the force of the standing tubes. For the simplifying of the calcula-tion, the influence of the diagonal brace on the force of the standing tubes was neglected. For safety, this paper used the conventional manual calculation method and the finite element analysis method of SAP2000 to calculate, the load value and bearing capacity of the formwork in accordance with JGJ162-2008 Techanical code for safety of forms in construction [5], JGJ231-2010 Techanical specification for safety of disk lock steel tubular scaffold in construction, GB50005-2017 Code for design of timber structure[6] and GB50429-2007 Code for design of aluminium structures [7]. The main calculation process is as follows:

\section{Manual calculation}

(1) Calculation of bearing capacity of slab

The single span simply supported beam was used to compute the slab, and the maximum bending normal stress of the section as follows:

$$
\sigma_{\max }=4.52 \mathrm{~N} / \mathrm{mm}^{2}<f_{m}=13 \mathrm{~N} / \mathrm{mm}^{2}
$$

The strength of the panel was satisfactory.

The maximum deflection of the midspan was calculated:

$$
\omega_{\max }=0.174 \mathrm{~mm}<[\omega]=0.375 \mathrm{~mm}
$$

Therefore, the $15 \mathrm{~mm}$ thick multi-layer plate met the requirements.

(2) Calculation of bearing capacity of secondary keel

Because of the spacing of main keel, the span of secondary keel is $0.9 \mathrm{~m}$, and $80 \mathrm{~mm} \times 80 \mathrm{~mm}$ wooden square was used as the secondary keel

The maximum stress of secondary keel was obtained as follows:.

$$
\sigma_{\text {max }}=8.59 \mathrm{~N} / \mathrm{mm}^{2}<f_{m}=13 \mathrm{~N} / \mathrm{mm}^{2}
$$

The strength of the secondary keel was satisfactory. Shear stress:

$$
\tau_{\max }=1.15 \mathrm{~N} / \mathrm{mm}^{2}<f_{v}=13 \mathrm{~N} / \mathrm{mm}^{2}
$$

The shear strength was satisfactory.

Deflection checking:

$$
\omega_{\max }=0.966 \mathrm{~mm}<[\omega]=2.25 \mathrm{~mm}
$$


The deflection was satisfactory.

Therefore, the keel was made of $80 \times 80 \mathrm{~mm}$ square timber, which meets the requirements.

\section{(3) Calculation of bearing capacity of main keel}

The main keel was laid transversely with a transverse span of $1.5 \mathrm{~m}$ and a spacing of $0.9 \mathrm{~m}$. used by 185 aluminium beams computing as follows:

Normal stress:

$$
\sigma_{\text {max }}=93.3 \mathrm{~N} / \mathrm{mm}^{2}<f=200 \mathrm{~N} / \mathrm{mm}^{2}
$$

The flexural strength was satisfactory.

The shear strength need not be checked because that section steel was used [8].

Deflection checking:

$$
\omega_{\max }=1.62 \mathrm{~mm}<[\omega]=3.75 \mathrm{~mm}
$$

Therefore, the keel was made of 185 aluminium beams, which met the requirements.

\section{(4) Bearing capacity calculation of support column}

Considering the deadweight of formwork and support, the deadweight of newly poured concrete and the live load of construction, a combination of various load effects was carried out, and the axial force design value $\mathrm{N}$ of one verti-cal bar in a unit was about $84.94 \mathrm{kN}$. The section of the vertical bar was not weakened, so the stability was checked only.

According to JGJ231-2010, the calculated length is $1800 \mathrm{~mm}$. From this calculation, the slenderness ratio of the column was $89.5<[\lambda]=150$, and the rigidity of it met the requirements too.

At the same time, according to formula 5.3.3-1 of the specification, the stability of the standing tubes was calcula-ted.

The cross section stress of the them:

$$
\sigma=268.5 \mathrm{~N} / \mathrm{mm}^{2}<f=300 \mathrm{~N} / \mathrm{mm}^{2}
$$

The stability of the bars met the requirements.

Therefore, the standing tubes adopted $\Phi 60 \times 3.2 \mathrm{~mm}$ meeting the requirements.

(5) Calculation of bearing capacity of base jack and U-head jack

Because the column may be eccentrically compressed, the minimum value of the bearing capacity of adjustable bracket was used $153 \mathrm{kN}$. To compute From the calculation, the design value of maximum bearing reaction was $84.94 \mathrm{kN}$, smaller than $153 \mathrm{kN}$. Therefore, the bearing capacity of support met the requirements.

\section{(6) Other aspects}

The support column of the formwork support of the roof falled on the concrete floor which had been constructed, so the bearing capacity of the support column foundation was no longer need to be calculated.

\section{Finite element analysis}

The structure composed of ledger and standing tube was a spatial form, while it was neglected in manual calculati-on that the relationship between horizontal and longitudinal frame. So the calculation method was less precise.For safety, the finite element analysis by SAP2000 was also used in this paper to analyze the frame structure [9]. According to the sub-warehouse situation of the main structure of the project in this area, the 6th warehouse, which was about $28 \mathrm{~m}$ long was taken out for modeling.To simplify the model, U-head jack was omitted in the modeling.According to the connection structure of the ledger and the standing tube the connection was simplified by the hinged connection. The load of roof formwork support was uniform load mainly.And a thin shell surface element was established in the finite element model to convert uniform load into frame loads. The final threedimensional model is shown in Fig. 3. After computing, the axial force of the members of transverse frame with larger force was obtained, the axial force of some of the vertical poles is shown in Fig. 4.

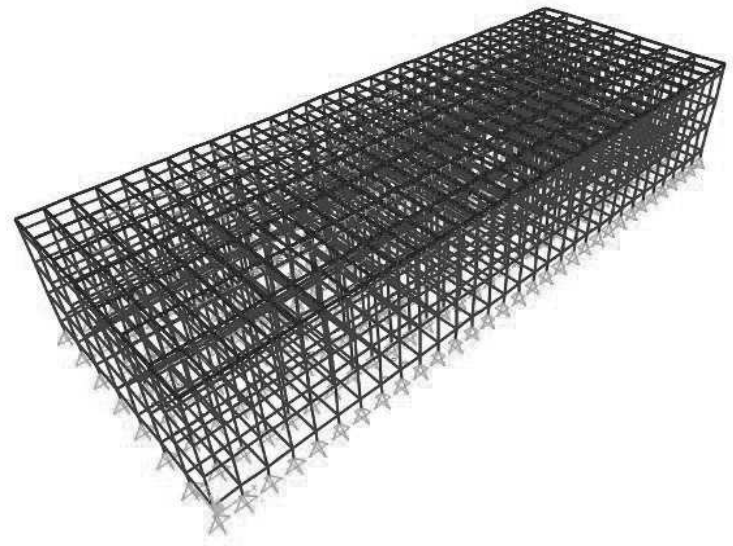

Fig. 3 Three-dimensional Model of the Form-work Support

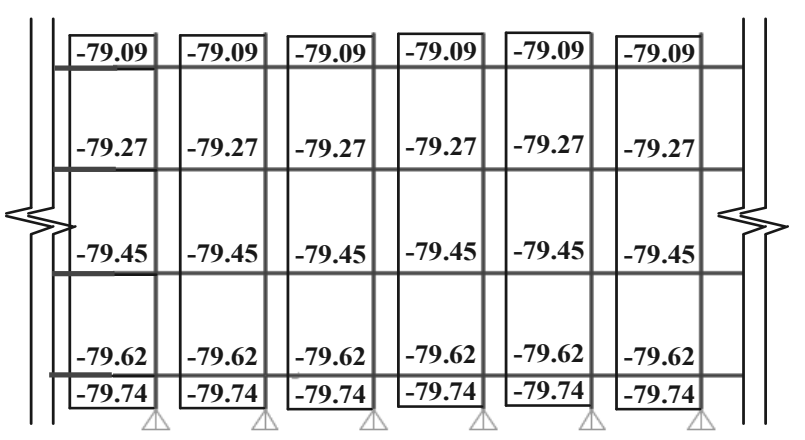

Fig. 4 Axis Force Diagram of Frame $(k N)$

According to Fig. 4, the maximum axial force of the column in the frame is $79.74 \mathrm{kN}$. According to JGJ2312010 , the stability stress of the cross section of the standing tube was obtained:

$$
\sigma=252.1 \mathrm{~N} / \mathrm{mm}^{2}<f=300 \mathrm{~N} / \mathrm{mm}^{2}
$$

From the above calculation results, it can be seen that the results of finite element analysis are little different from those of manual calculation. Because of the space effect of the formwork, the finite element analysis is more advan-tageous to the force of the column, which results in the calculation results being slightly smaller than those of manual calculation. 
4.3 Influence of diagonal brace to the force of formwork support member

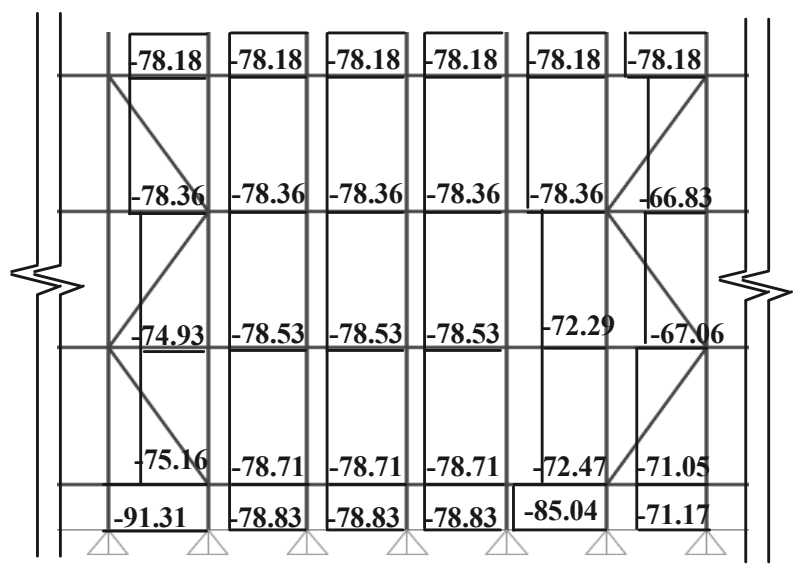

Fig. 5 Axis Force Diagram of Members of Frame with Little Diagonal Brace $(k N)$

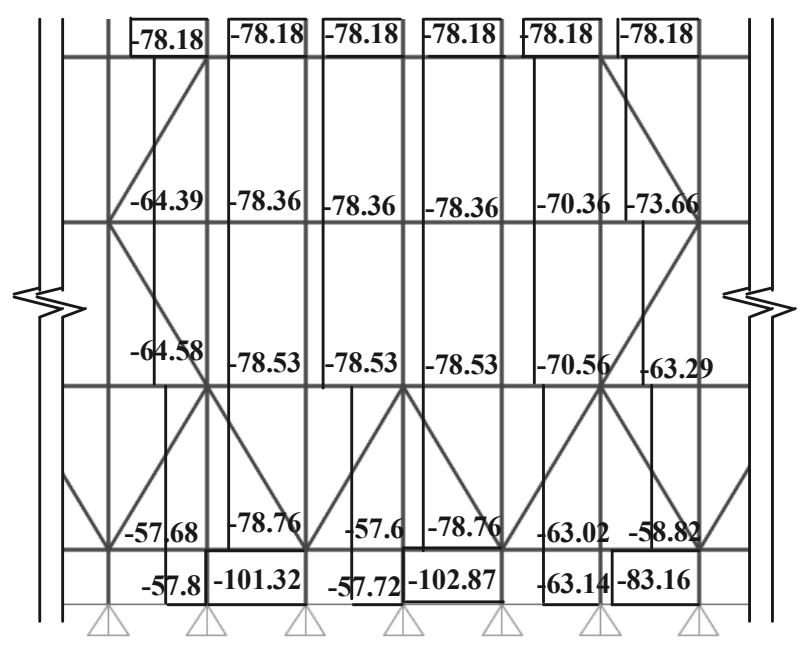

Fig. 6 Axis Force Diagram of Members of Frame with More Diagonal Brace $(k N)$

At present, in the design of formwork support in JGJ231-2010, the layout of diagonal brace still follows the "Tech-nical Code for Safety of Steel Tubular Scaffold with Couplers in Construction" for diagonal brace.
For the stiffness of the diagonal brace, its setting will affect the force of other adjacent members in the formwork frame.And the finite element method of SAP2000 was used to analyze the force of formwork frames under $1.5 \mathrm{~m}$ thick roof with no, several and brace number complying with the specification (referred to as multi- diagonal brace). For comparison, the three cases were analyzed by taking out the most stressed parts of the whole frame. It was found that the most stressed members in each model appeared in the 4th longitudinal frame. And the axial force of members of the frame is shown in Fig. 5 6.

Fig. 5 represents the axial force diagram of the longitudinal second to seventh parts of the frame without diagonal brace. It can be seen that the force of the rods without diagonal brace shown in the figure is more uniform, but the system of the formwork with diagonal brace is not. From Fig. 5 to 6 , it can be seen that with the increase of the number of diagonal brace in the frame, the distribution of the axial force of the member tends to be uneven. Especially, the maximum axial force of the rod reaches 102.87 $\mathrm{kN}$ when the diagonal brace was set up according to the specification. From this, the stability of the rod is calculated according to the formula 5.3-1 of the specification, and the cross-sectional stress of the rod is $325.2 \mathrm{~N} / \mathrm{mm} 2$, which exceeds the strength design value of Q345 steel, $\mathrm{N} / \mathrm{mm} 2$. The force of each member of the frame with brace is relatively uniform. The maximum axial force of the member is $74.74 \mathrm{kN}$, and the stable stress is 252.1 $\mathrm{N} / \mathrm{mm} 2$. There is a big discrepancy between them. In practical engineering, the design of formwork frame is mostly design by manual caculation, and for the simplicity of calculation, the brace is often neglected for force analysis. Finally, the diagonal brace is set up in accordance with thespecification. According to the results of the finite element analysis in this paper, not considering the set of diagonal brace in the calculation will bring unsafty to the design of the die frame.

In order to analyze the influence of diagonal brace on the overall force to the formwork frame more intuitively, part of the bar were taken part from the three types of formwork frames mentioned above separately. The comparison has been made for the axial force and the stress of the cross-section of the members calculated according to the stabili-ty, which was shown in Table 2.

Tab. 2 Comparison of forces on partial member of the three formwork support

\begin{tabular}{|c|c|c|c|c|c|}
\hline Brace type & $\begin{array}{l}\text { Member } \\
\text { number }\end{array}$ & $\begin{array}{l}\text { Axial force of mem- } \\
\text { bers }(\mathrm{kN})\end{array}$ & $\begin{array}{l}\text { Increase than no dia- } \\
\text { gonal brace }(\%)\end{array}$ & $\begin{array}{c}\text { Stress } \\
\left(\mathrm{N} / \mathrm{mm}^{2}\right)\end{array}$ & $\begin{array}{l}\text { Whether the strength met } \\
\text { the requirement }\end{array}$ \\
\hline \multirow{3}{*}{ No diagonal brace } & 1 & 79.74 & - & 252.08 & Yes \\
\hline & 1 & 91.31 & 14.51 & 288.65 & Yes \\
\hline & 2 & 87.79 & 10.10 & 277.52 & Yes \\
\hline \multirow{7}{*}{ Vertical diagonal brace } & 3 & 85.04 & 6.65 & 268.83 & Yes \\
\hline & 4 & 84.83 & 75.03 & 268.17 & Yes \\
\hline & 5 & 84.04 & 5.39 & 265.67 & Yes \\
\hline & 1 & 102.87 & 29.01 & 325.19 & No \\
\hline & 2 & 102.4 & 28.42 & 323.71 & No \\
\hline & 3 & 101.86 & 27.74 & 322.00 & No \\
\hline & 4 & 101.74 & 19.64 & 321.62 & No \\
\hline \multirow{5}{*}{$\begin{array}{c}\text { Vertical and horizontal } \\
\text { diagonal brace }\end{array}$} & 5 & 101.32 & 27.06 & 320.29 & No \\
\hline & 6 & 99.27 & 24.49 & 313.81 & No \\
\hline & 7 & 99.06 & 24.23 & 313.15 & No \\
\hline & 8 & 99.04 & 24.20 & 313.09 & No \\
\hline & 9 & 98.55 & 23.59 & 311.54 & No \\
\hline
\end{tabular}


From Table 2, it can be seen the increasing of internal force of more standing tube in the formwork support system with diagonal brace set up according to the requirements of the specification. And the axial force of these members increased by more than $20 \%$ than that without diagonal brace, which directly led to the insufficiency of the stable bea-ring capacity of these bars. So you can see that the existence of diagonal braces has great influence on the force of the connecting standing tube of the formwork support.

\section{Conclusion}

In this paper, SAP2000 finite element analysis software and manual calculation were used to design and calculate the disk lock steel tubular scaffold under $1.5 \mathrm{~m}$ thick plate in a metro section project. The following conclusions were obtained through the calculation:

(1) For the $1.5 \mathrm{~m}$ thick slab support system in this paper, the results of the finite element analysis software SAP2000 without considering the influence of diagonal brace are similar to those of the manual calculation.

(2) The existence of diagonal brace will make the force of the standing tubes in the support system tend to be uneven. With the increase of the number of brace the uneven degree will become more serious.

(3) Manual calculation neglects the diagonal brace and conducts the stress analysis and even the bearing capacity calculation of members, which will bring unsafe factors to the use of formwork support in construction.

\section{References}

[1] SHEN, Q., LIU, H.L. (2016). Application of socket type steel pipe scaffolds system on TRON lightcycle power run project. In: Construction Technology, Vol. 45, No. 15, pp. 27

[2] DUAN, J., BAN, Y.X., XIAO, M.K., ZHANG, Q. (2017). Defect analysis on calculation method of bearing capac-ity of the mew socket button type formwork supporting system. In: Science Technology and Engineering, Vol. 17, No. 26, pp. 285.

[3] XU, R., LIU, B.B., MA, R.Q. (2014). Experimental study on formwork support system with disk lock steel tubu-lar. In: Construction Technology, No. 15, pp. 77.

[4] Ministry of Development of the People's Republic of China. (2010). JGJ231-2010Techanical specification for safety of disk lock steel tubular scaffold in construction. Beijing: China architecture \& building press, pp. 12, 16, 17, 22.

[5] Ministry of Development of the People's Republic of China. (2008). JGJ162-2008Techanical code for safety of forms in construction. Beijing: China Architecture \& Building Press, pp. 15.

[6] Ministry of Development of the People's Republic of China. (2017). GB50005-2017Code for design of timber structure. Beijing: China Architecture \& Building Press, pp. 38 - 39.

[7] Ministry of Development of the People's Republic of China. (2008). GB50429-2007 Code for design of alumin-ium structures. Beijing: China Planning Press, pp. 32.

[8] JANDA, T. (2018). Use of metallographic analysis for evaluating microstructures in quenched and tempered high-strength steel. In: Manufacturing Technology, Vol. 18, No. 1, pp. 47 - 52

[9] SOUKUP, J., KLIMENDA, F., SKOČILAS, J., ŽMINDÁK, M. (2019). Finite element modelling of shock wave propagation over obstacles. In: Manufacturing Technology, Vol. 19, No. 3, pp. $499-507$. 